\title{
PENGAPLIKASIAN TEKNIK BLOCK PRINTING DENGAN MATERIAL KAYU BEKAS KEBAKARAN HUTAN KALIMANTAN BARAT PADA PAKAIAN READY TO WEAR
}

\author{
Tione Afifaya Dumamika ${ }^{*}$, Mochammad Sigit Ramadhan ${ }^{2 *}$
}

\author{
Program Studi Kriya Tekstik dan Fashion Fakultas Industri Kreatif \\ Universitas Telkom \\ Jl. Telekomunikasi, No. 1, Terusan Buahbatu-Bojongsoang, Kec. Dayeuhkolot, Kota Bandung, Kode Pos 40257 \\ Jawa Barat. Indonesia \\ Email: tioneafifaya@gmail.com,sigitrmdhn@telkomuniversity.ac.id
}

\begin{abstract}
Abstrak
Block printing adalah teknik memproduksi gambar secara berulang pada suatu permukaan yang menghasilkan karya orisinil dan unik, karena dilakukan secara manual. Tetapi seiring berjalannya waktu, block printing masih kurang dikenal dan kurang berkembang di Indonesia. Bahan untuk membuat plat cetak block printing dapat diganti dengan berbagai material alternatif, seperti kayu bekas kebakaran hutan. Kayu bekas kebakaran hutan seringkali sudah tidak memiliki nilai jual dan hanya dapat dijadikan arang atau kayu bakar oleh masyarakat sekitar. Tujuan dari penelitian ini yaitu mendapatkan solusi untuk memanfaatkan dan meningkatkan nilai kayu bekas kebakaran hutan yang sudah tidak terpakai menjadi plat cetak block printing. Berkaitan dengan hal tersebut, maka penulis terinspirasi untuk menggunakan kayu bekas kebakaran hutan sebagai plat cetak block printing agar dapat menaikkan nilai seni dan ekonomi kayu, juga dapat memberikan image baru pada permukaan tekstil dan produk fashion. Penelitian dilakukan dengan metode penelitian kualitatif berupa observasi yang dilakukan dengan cara mengamati langsung kondisi kayu bekas kebakaran hutan, studi literatur mengenai topik penelitian didapatkan dari beberapa jurnal, buku, dan artikel, dan eksperimen yang terdiri dari beberapa percobaan eksplorasi awal, lanjutan dan terpilih. Produk yang dihasilkan dari penelitian ini berupa lembaran kain dan koleksi pakaian ready to wear.
\end{abstract}

Kata Kunci: block printing, kayu bekas, fashion.

\begin{abstract}
Block printing is a technique of producing images repeatedly on a surface that produces original and unique work because it was done manually. However, as time goes by, block printing is still less well known and less developed in Indonesia. In addition to the newly used wood, block printing plates can be replaced by various alternative materials, such as wood from forest fires. Unfortunately, wood from forest fires often has no selling value and can only be used as charcoal or firewood by the surrounding community. This research aims to find a solution to utilize and increase the value of unused forest fires wood into block printing plates. The author was inspired to use forest fires wood as a block printing plate to increase the artistic and economic value of wood and give a new image to the surface of textiles and fashion products. This research was carried out using qualitative research methods in the form of observations made by observing the condition of wood from forest fires directly; literature studies are obtained from several journals, books, and articles; also, experiments consisting of initial, advanced, and selected experiments. The products produced from this research are sheets of cloth and a collection of ready-to-wear clothing.
\end{abstract}

Keywords: block printing, wood residue, fashion.

\section{PENDAHULUAN}

Block printing merupakan teknik cetak tinggi yang termasuk dalam teknik cetak konvensional seni grafis. Perkembangan block printing telah ada sejak zaman dahulu, awal mulanya block printing diaplikasikan pada dinding gua. Material plat block printing yang banyak digunakan pada saat itu adalah batu atau kayu yang digores (Kafka, 1973). Block printing juga merupakan teknik cetak tertua yang berfungsi sebagai sarana untuk memproduksi gambar atau tulisan secara berulang pada suatu permukaan (Needleman, 2018). Teknik block printing memiliki kelebihan yaitu dapat menghasilkan karya seni orisinil yang memiliki keunikan dan desain berbeda satu sama lain, karena dikerjakan secara manual (Ganguly \& Amrita, 2013). Untuk melakukan teknik block printing tidak diperlukan bahan dan peralatan khusus. Bahan untuk membuat plat cetak block printing dapat diganti dengan 
berbagai material alternatif, dengan syarat benda tersebut memiliki ketebalan permukaan yang berbeda, dapat digunakan secara berulang, dan permukaannya dapat diberi pewarna (Puspitawati \& Ramadhan, 2019). Teknik block printing juga dapat diaplikasikan di berbagai material cetak seperti kain, kertas, plastic, dll. Sehingga, teknik ini memiliki peluang besar untuk terus berkembang dari masa ke masa.

Berkaitan dengan hal tersebut, mengganti penggunaan material plat cetak block printing menggunakan barang bekas merupakan salah satu inovasi yang dapat dilakukan pada penelitian ini. Dengan mengolah barang bekas yang sudah tidak terpakai menjadi suatu karya inovatif dapat memberikan keuntungan seperti meningkatkan imajinasi, mengembangkan kreativitas, dan pastinya menghemat dana (Rohani, 2017). Salah satu barang bekas yang berpotensi untuk dijadikan material plat cetak alternatif block printing adalah kayu bekas. Material kayu bekas dapat diperoleh dari alam, kemasan, industri kayu skala besar maupun kecil, dan sisa bahan bangunan. Kayu bekas termasuk salah satu jenis barang bekas yang memiliki potensi dan berfungsi menjadi sesuatu yang lebih bermanfaat jika diolah dengan benar (Safitri \& Rachmat, 2016). Dalam pemanfaatannya, mengolah kayu bekas menjadi suatu karya seni merupakan salah satu solusi untuk meningkatkan nilai jual kayu bekas (Eskak \& Sumarno, 2016).

Pada penelitian ini, peneliti memanfaatkan kayu bekas kebakaran hutan Kalimantan Barat untuk dijadikan material plat cetak alternatif block printing. Berdasarkan data luas kebakaran hutan dan lahan dari Kementerian Lingkungan Hidup dan Kehutanan (KLHK) pada website resmi SiPongi Karhutla Monitoring Sistem, diketahui bahwa rekapitulasi luas kebakaran hutan dan lahan di Kalimantan Barat pada tahun 2020 sampai tanggal 30 September 2020 mencapai 6.131 hektar. Hal ini mengakibatkan meningkatnya kayu bekas terbakar, yang selama ini hanya dijadikan arang atau kayu bakar oleh masyarakat sekitar. Padahal bentuk kayu yang unik dan tekstur permukaan yang tidak rata dapat berpotensi menghasilkan motif dengan karakteristik visual yang khas pada permukaan material tekstil apabila dimanfaatkan sebagai plat cetak alternatif block printing.

Dalam implementasinya, material tekstil yang permukaannya telah diolah dengan teknik block printing tersebut dapat berpeluang untuk digunakan dalam perancangan produk fashion. Salah satu diantaranya adalah produk pakaian ready to wear
Gorga : Jurnal Seni Rupa

Volume 10 Nomor 02 Juli-Desember 2021 p-ISSN: 2301-5942 | e-ISSN: 2580-2380

dengan desain yang tetap menonjolkan karakter visual yang khas dari hasil cetak kayu bekas kebaran hutan Kalimantan Barat.

Berdasarkan pemaparan latar belakang dan fenomena yang telah disampaikan, peneliti merumuskan beberapa hal yang menjadi tujuan penelitian yaitu: 1). Memanfaatkan potensi kayu bekas kebakaran hutan Kalimantan Barat sebagai material plat cetak alternatif dalam rangka mengembangkan teknik block printing. 2). Mengolah komposisi motif dengan tepat agar menghasilkan karakter visual dari kayu bekas kebakaran hutan Kalimantan Barat yang baru dan unik pada material tekstil menggunakan teknik block printing. 3). Mengaplikasikan lembaran tekstil yang telah diolah dengan teknik block printing pada produk fashion busana ready to wear dengan tetap menonjolkan karakteristik visual dari hasil pencetakan kayu bekas kebakaran hutan Kalimantan Barat.

\section{KAJIAN TEORI}

\section{Block Printing}

Block printing adalah teknik mencetak teks, gambar atau motif yang menggunakan cetakan blok kayu atau logam. Block printing berfungsi sebagai sarana untuk memproduksi gambar atau tulisan secara berulang pada suatu permukaan menggunakan alat cetak yang diukir dan diberi pewarna. Block printing merupakan teknik cetak tinggi (relief print) yang termasuk dalam teknik cetak konvensional seni grafis (Adi et al., 2020). Teknik ini memiliki kelebihan yaitu dapat menghasilkan karya seni orisinil yang memiliki keunikan dan desain berbeda satu sama lain, karena dikerjakan secara manual (Ganguly \& Amrita, 2013).

Perkembangan block printing telah ada sejak zaman dahulu, awal mulanya block printing di aplikasikan pada dinding gua. Material plat block printing yang banyak digunakan pada saat itu adalah batu atau kayu yang digores (Kafka, 1973). Berdasarkan data perkembangan block printing di India pada website resmi The Kindcraft, diketahui bahwa meskipun teknik block printing diyakini berasal dari abad ke-14, tetapi pada abad ke-3 sudah ditemukan kain cetak Rajasthani antik. Dikatakan juga teknik ini berasal dari Cina sekitar ribuan tahun yang lalu. Teknik block printing merupakan teknik cetak tertua yang berfungsi untuk mencetak teks dan gambar ilustrasi di atas kertas (Needleman, 2018). Kemudian sekitar abad ke-15, teknik block printing mulai banyak digunakan secara khusus untuk membuat gambar tanpa teks di Eropa (Rahman, 2017). 
Gorga : Jurnal Seni Rupa

Volume 10 Nomor 02 Juli-Desember 2021

p-ISSN: 2301-5942 | e-ISSN: 2580-2380

\section{1). Plat Cetak}

Terdapat dua jenis plat cetak block printing berdasarkan cetakan motif yang dihasilkan, yaitu: 1). Outlining block (rekh): balok yang memberikan motif berwarna pada bagian garis luar motif. 2). Filling block (gadh): balok yang memberikan warna pada bagian dari isi motif.

Berdasarkan material pembuatnya, terdapat beberapa jenis penggunaan material pada plat cetak block printing, yaitu: 1). Wooden block: balok terbuat dari kayu jati atau seesham, yang diukir secara manual. 2). Metal block: balok terbuat dari ukiran lembaran tipis potongan logam dengan ukuran yang sama ke dalam balok kayu. 3). Rubber block: balok terbuat dari karet linoleum, dan biasanya dipasang pada balok kayu. 4). Alternative block: balok ini terbuat dari material apapun yang memiliki permukaan dan dapat menghasilkan gambar. Material yang ada disekitar dan ada dalam kehidupan sehari-hari, seperti buah, plastik, alat makan, dll. dapat dijadikan sebagai balok.

\section{2). Pewarna}

Terdapat dua jenis pewarna berdasarkan zat pelarutnya, yaitu: 1). Water-based: pewarna dengan komponen mayoritas air. Jenis pewarna ini merupakan pewarna yang cepat kering saat diaplikasikan dan tidak mudah retak ketika terpapar suhu panas maupun dingin, karena dapat mengikuti dinamika suhu. 2). Oil-based: pewarna berbasis minyak yang mengandung Volatile Organic Compounds (VOC), senyawa organik yang mudah menguap, dan memiliki efek buruk bagi kesehatan dan kelestarian alam. Namun, pewarna jenis ini akan lebih awet saat digunakan.

\section{Kayu Bekas}

Kayu bekas adalah kayu yang sudah pernah dipakai, tertinggal atau tersisa, terbakar, ataupun pernah diolah menjadi sesuatu. Kayu bekas termasuk salah satu jenis barang bekas yang memiliki potensi dan berfungsi menjadi sesuatu yang lebih bernilai dan bermanfaat jika diolah dengan benar (Safitri \& Rachmat, 2016). Berikut merupakan beberapa tempat asal kayu bekas: 1). Alam. 2). Packing dan shipping. 3). Industri skala kecil. 4). Industri skala menengah dan besar. 4). Struktur dan sisa bangunan.

\section{Kebakaran Hutan}

Ada banyak faktor yang menyebabkan terjadinya kebakaran hutan. Kebakaran hutan biasanya disebabkan oleh alam seperti petir dan lava gunung berapi. Namun seringkali kebakaran hutan dan lahan disebabkan oleh kelalaian atau perilaku manusia yang disengaja. Konversi lahan, pembakaran vegetasi, pemanfaatan sumber daya alam, pemanfaatan lahan gambut, dan sengketa lahan merupakan penyebab kebakaran hutan yang dilakukan manusia (Qodriyatun, 2014). Selain itu, musim kemarau juga dapat menyebabkan kebakaran hutan. Kebakaran hutan dan lahan (karhutla) selama musim kemarau di berbagai wilayah Indonesia terus terjadi.

\section{1). Kebakaran Hutan di Kalimantan Barat}

Berdasarkan data luas kebakaran hutan dan lahan dari Kementerian Lingkungan Hidup dan Kehutanan (KLHK) pada website resmi SiPongi Karhutla Monitoring Sistem, diketahui bahwa rekapitulasi luas kebakaran hutan dan lahan di Kalimantan Barat pada tahun 2020 sampai tanggal 30 September 2020 mencapai 6.131 hektar. Kebakaran hutan memberikan dampak buruk seperti rusaknya ekosistem, hilangnya potensi hutan, dan kabut asap. Hilangnya potensi hutan, terutama kayu sangat berpengaruh bagi kehidupan masyarakat dikarenakan berdasarkan data BPS (Badan Pusat Statistik), Kalimantan merupakan salah satu penghasil kayu terbesar di Indonesia.

\section{2). Kayu Bekas Kebakaran Hutan}

Salah satu dampak kebakaran hutan yaitu adanya limbah kayu bekas kebakaran hutan. Kayu-kayu ini merupakan kayu bekas yang berasal dari alam, yang sudah terbakar dan tidak dapat bernilai ekonomi lagi. Terdiri dari beberapa jenis pohon, berupa ranting dan batang pohon yang kebanyakan masih berukuran kecil. Sehingga, biasanya kayu bekas kebakaran hutan ini hanya dijadikan sebagai kayu bakar atau arang oleh masyarakat sekitar.

\section{Fashion}

Fashion secara etimologi berasal dari bahasa latin, 'factio' yang artinya melakukan. Maksud melakukan berarti mengacu pada semua kegiatan yang dilakukan oleh seseorang. Fashion merupakan media untuk berekspresi, berimajinasi, dan bentuk komunikasi untuk memperlihatkan identitas, status, kepribadian, dan perasaan pemakainya. Fashion mencakup segala sesuatu yang berkaitan dengan perkembangan tren, busana, gaya hidup, tradisi maupun budaya yang berkaitan dengan kehidupan sosial manusia (Trisnawati, 2016)

Pada dasarnya, fashion berfungsi sebagai penutup yang melindungi diri dari cuaca. Namun saat ini, fashion tidak hanya memperhatikan nilai guna, tetapi juga untuk menyampaikan pesan dan nilai tersirat seseorang yang mengenakannya (Lestari, 2014). Hal ini dibuktikan dengan kota-kota besar eropa sebagai pusat 


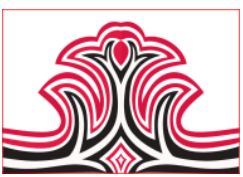

fashion dunia seperti London, Paris, New York dan Milan.

Dalam industri fashion, secara mendasar fashion dapat diklasifikasikan dalam berbagai kategori seperti gender, usia, musim ataupun ouput produk akhir yang didasari oleh proses produksi. Namun, terdapat klasifikasi yang membedakan level manufaktur produk fashion berdasarkan tingkat keunggulan, kualitas, dan keangkuhan yaitu couture, ready to wear, dan mass product (Waddell, 2004).

\section{1). Couture}

Haute Couture berasal dari bahasa Prancis, "haute" yang berarti tinggi dan "couture" yang berarti tata busana atau menjahit. Haute Couture merupakan jenis klasifikasi fashion yang eksklusif dengan standar produksi khusus atau custom-made, mahakarya tertinggi di dunia mode karena dirancang sesuai ukuran tubuh konsumen. Haute Couture juga menggunakan pola dan detail yang rumit, waktu pengerjaan yang lama, serta bahan dan material dengan kualitas tertinggi. Haute couture dibuat dua kali setahun dengan koleksi spring / summer dan fall / winter, yang terdiri dari berbagai macam pakaian seperti ball gown, evening gown, dan jas.

\section{2). Ready to Wear}

Ready to wear merupakan pakaian siap pakai yang juga disebut Pret-a-porter, sudah ada sejak zaman Perang Dunia I. Pada tahun 1914 sampai 1918, pakaian ready to wear diproduksi menjadi seragam untuk tentara di Belgia dan Prancis.

Pakaian ready to wear dibuat dengan ukuran standar, tanpa melalui pengukuran khusus dan dirancang untuk dapat dipakai oleh berberapa jenis ukuran tubuh. Pakaian ready to wear bisa didapatkan di berbagai store, diproduksi secara massal, dan bisa dipakai sehari-hari. Namun pakaian ready to wear juga menuntut kualitas produk yang lebih tinggi jika dibandingkan dengan pakaian mass production.

\section{3). Mass Production}

Mass product atau yang biasa disebut dengan fast fashion merupakan pakaian ready to wear yang diproduksi oleh industri garmen dengan jumlah kuantitas produksi yang tinggi, cakupan pasar yang sangat luas dan menggunakan material dan bahan yang berkualitas standar. Harganya pun relatif murah karena diproduksi secara massal, tingkat kerumitan yang rendah, dan perputaran musimannya sangat cepat sesuai dengan tren yang berkembang.
Gorga : Jurnal Seni Rupa

Volume 10 Nomor 02 Juli-Desember 2021 p-ISSN: 2301-5942 | e-ISSN: 2580-2380

\section{METODE PENELITIAN}

Metode yang digunakan pada penelitian ini adalah metode penelitian kualitatif dengan beberapa metode untuk mendapatkan data yang valid yaitu metode observasi, studi literatur dan eksperimen.

\section{Observasi}

Observasi dilakukan dengan pengamatan langsung yang disertai dokumentasi terhadap kondisi hutan dan kayu bekas terbakar di beberapa hutan yang ada di daerah Kota Pontianak Selatan, Pontianak Tenggara, dan Kabupaten Kubu Raya untuk mengetahui keadaan, jenis, dan ukuran kayu bekas kebakaran hutan yang berpotensi untuk dimanfaatkan.

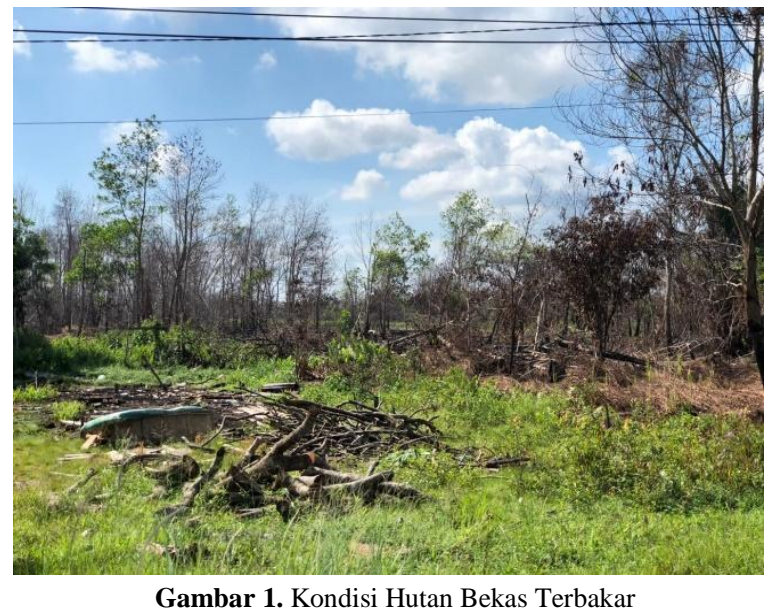

Gambar 1. Kondisi Hutan Bekas Terbakar (Dumamika, 2021)

Berdasarkan hasil observasi, ditemukan bahwa hutanhutan ini sempat terbakar saat musim kemarau atau sengaja dibakar untuk membuka lahan, namun sekarang sudah ditumbuhi tanaman baru. Hal ini dikarenakan observasi dilakukan saat musim hujan. Jenis pohon yang terdapat pada hutan bekas terbakar ini yaitu pohon pinang, pohon sawit, dan pohon akasia. Didapatkan juga bahwa banyak kayu bekas kebakaran hutan yang ditumpuk dan dibiarkan begitu saja, tidak dimanfaatkan untuk membuat sesuatu yang lebih bernilai dan bermanfaat. Kayu bekas kebakaran hutan yang berpotensi untuk dimanfaatkan pada penelitian adalah kayu akasia dengan ukuran diameter 2-8 cm. 

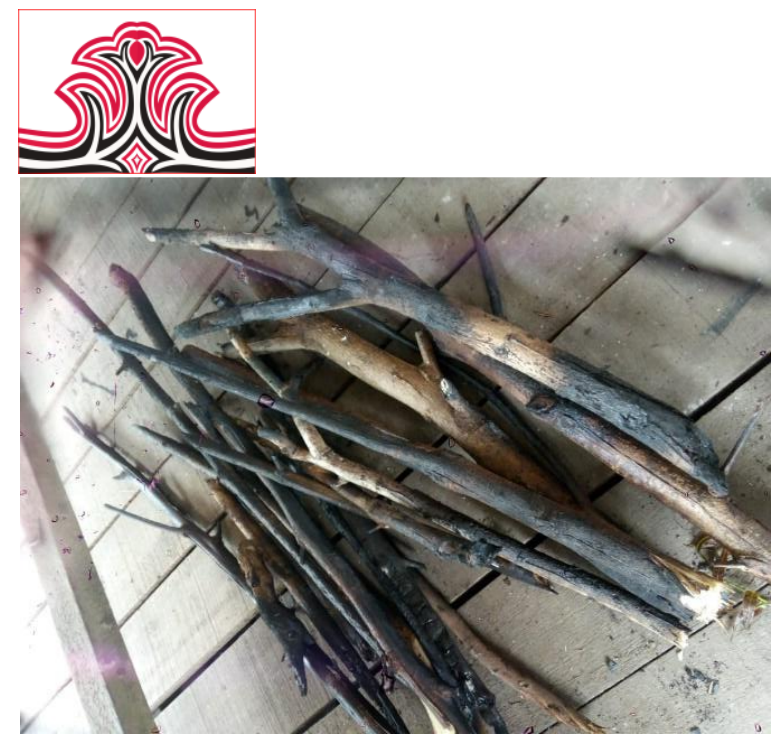

Gambar 2. Kayu Bekas Kebakaran Hutan (Dumamika, 2020)

\section{Studi Literatur}

Pengumpulan data, informasi, dan referensi melalui studi literatur berupa buku, artikel, dan jurnal mengenai block printing, kayu bekas kebakaran hutan, dan fashion dilakukan untuk mendukung topik penelitian. Adapun buku yang menjadi rujukan utama yaitu "Cetak Tinggi dan Pengaplikasiannya" yang ditulis oleh Adi dkk. pada tahun 2020.

Berdasarkan artikel pada website resmi Media Indonesia, diketahui bahwa kayu bekas kebakaran hutan dapat diolah menjadi cuka kayu sehingga bernilai ekonomi dan dapat menjadi solusi untuk mengatasi kebakaran hutan. Berdasarkan artikel pada website resmi Kementerian Lingkungan Hidup dan Kehutanan Republik Indonesia, dikatakan bahwa banyaknya limbah kayu bekas kebakaran hutan merupakan suatu ancaman karena menghasilkan kayukayu yang tidak dibutuhkan. Oleh karena itu, limbah kayu diolah menjadi arang kompos dan cuka kayu agar lebih bermanfaat. Namun, selain itu belum ada inovasi pengolahan dengan cara lain untuk memanfaatkan kayu bekas kebakaran hutan menjadi sesuatu yang lebih bernilai lagi.

Kesimpulan dari data yang didapatkan yaitu peneliti dapat berinovasi dalam mengolah kayu bekas kebakaran hutan sebagai material alternatif plat cetak block printing agar dapat memanfaatkan, menaikkan nilai seni, dan nilai ekonomi kayu bekas kebakaran hutan.

\section{Eksperimen}

Pada penelitian dengan metode eksperimen terdiri dari beberapa percobaan eksplorasi teknik block printing pada kayu bekas kebakaran hutan, lembaran tekstil, dan beberapa jenis pewarna melalui eksplorasi awal, lanjutan, dan terpilih.
Gorga : Jurnal Seni Rupa

Volume 10 Nomor 02 Juli-Desember 2021 p-ISSN: 2301-5942 | e-ISSN: 2580-2380

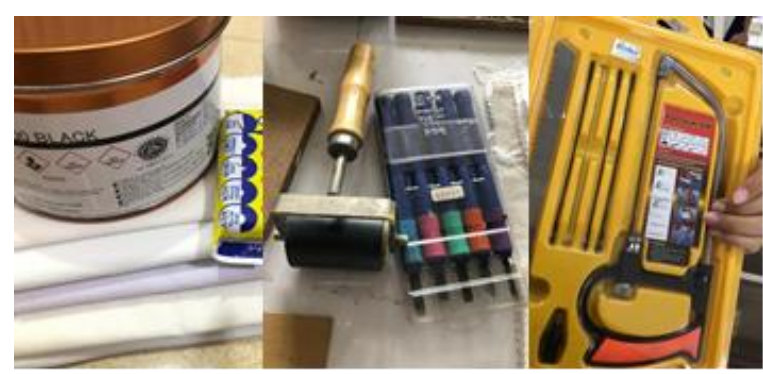

Gambar 3. Alat dan Bahan Eksplorasi. Bandung. (Dumamika, 2020)

\section{HASIL DAN PEMBAHASAN}

\section{Hasil}

\section{1). Eksplorasi Awal}

Eksplorasi awal dilakukan pada plat cetak, beberapa media cetak (kain), dan beberapa jenis pewarna. Eksplorasi pada plat cetak dilakukan dengan mengolah kayu bekas kebakaran hutan menggunakan beberapa teknik.

Tabel 1. Eksplorasi Awal

\begin{tabular}{|c|c|c|}
\hline Modul Plat Cetak & Hasil Cetak & Proses Pengerjaan \\
\hline & & $\begin{array}{l}\text { Batang kayu berukuran } \\
\text { diameter } 5 \mathrm{~cm} \text { diolah } \\
\text { dengan teknik potong } \\
\text { gecara horizontal. } \\
\text { Permukaan plat batang } \\
\text { kayu yang sudah } \\
\text { dipotong dilapisi tinta } \\
\text { offeet, kemudian di cetak } \\
\text { pada kain katun jepang. }\end{array}$ \\
\hline & & $\begin{array}{l}\text { Batang kayu diolah } \\
\text { dengan teknik potong } \\
\text { gecara horizontal. } \\
\text { Permukaan plat batang } \\
\text { kayu yang sudah } \\
\text { dipotong menjadi plat } \\
\text { cetak dengan ukuran } 6 \\
\mathrm{~cm} x 5 \mathrm{~cm} \text { dilapisi tinta } \\
\text { offset, kemudian di cetak } \\
\text { pada kain katum jepang. }\end{array}$ \\
\hline & & $\begin{array}{l}\text { Batang kayu berukuran } \\
\text { diameter } 7 \mathrm{~cm} \text { diolah } \\
\text { dengan teknik potong } \\
\text { gecara horizontal. } \\
\text { Permukaan plat batang } \\
\text { kayu yang sudah } \\
\text { dipotong dilapisi tinta } \\
\text { offeet, kemudian di cetak } \\
\text { pada kain katun jepang. }\end{array}$ \\
\hline & & $\begin{array}{l}\text { Beberapa batang kayu } \\
\text { diolah dengan teknik } \\
\text { potong gecara horizontal, } \\
\text { digabungkan menjadi } \\
\text { satu plat, dan di cukil } \\
\text { Permukaan plat batang } \\
\text { kayu yang sudah } \\
\text { dipotong dan dicukil }\end{array}$ \\
\hline
\end{tabular}



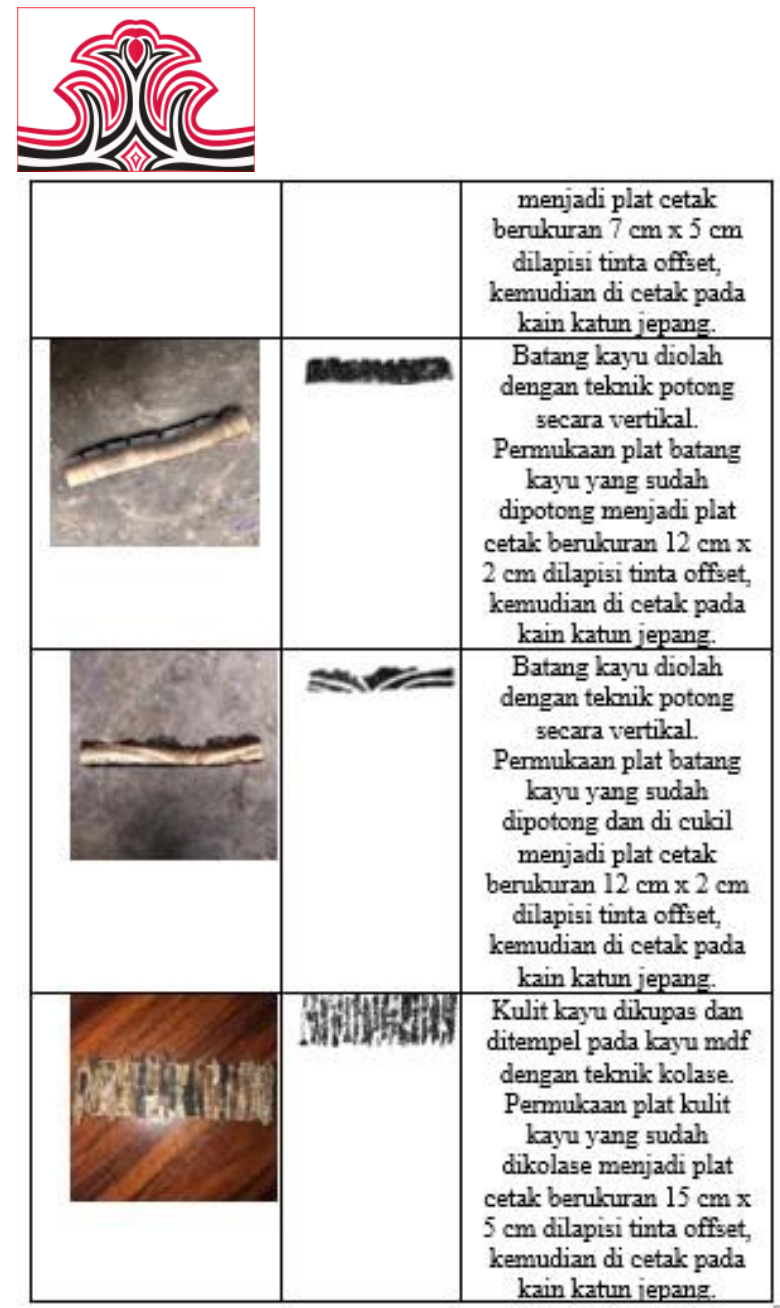

(Dumamika, 2020)

\section{2). Eksplorasi Lanjutan}

Pada eksplorasi lanjutan dilakukan proses perancangan motif secara digital, mengkomposisikan motif dengan cara menggabungkan beberapa modul yang berbeda, dengan mempertimbangkan unsur rupa, menggunakan prinsip desain, dan berbagai teknik pengulangan motif.

Tabel 2. Eksplorasi Lanjutan

\begin{tabular}{|c|c|c|}
\hline Modul & Komposisi Motif & Deskripsi \\
\hline 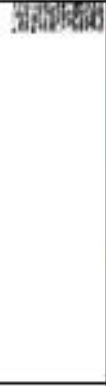 & 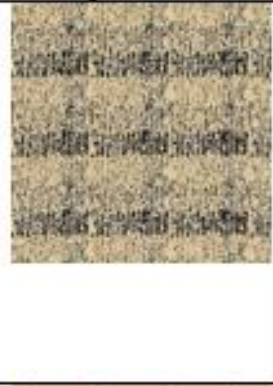 & $\begin{array}{l}\text { Membuat komposisi } \\
\text { rancangan motif dengan } \\
\text { aplikasi Corel Draw, } \\
\text { berukuran } 90 \mathrm{~cm} \text { x } 90 \mathrm{~cm} \text {, } \\
\text { dengan menggunakan } \\
\text { telmik full-drop repeat. } \\
\text { Komposisi pada image } \\
\text { berikut memilik unsur } \\
\text { desain bidang, dan tekstur. } \\
\text { Serta prinsip desain } \\
\text { kegatuan, keseimbangan, } \\
\text { dan irama. }\end{array}$ \\
\hline 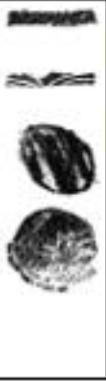 & 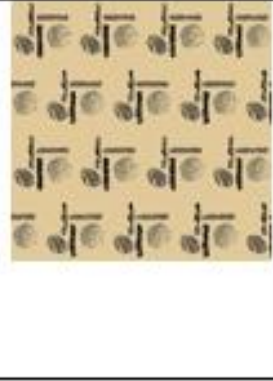 & $\begin{array}{l}\text { Membuat komposisi } \\
\text { rancangan motif dengan } \\
\text { aplikasi Corel Draw, } \\
\text { berukuran } 90 \mathrm{~cm} \text { x } 90 \mathrm{~cm} \text {, } \\
\text { dengan menggunakan } \\
\text { teknik brick pattern } \\
\text { repeat. Komposisi pada } \\
\text { image berikut memilik } \\
\text { unsur desain titik, garis, } \\
\text { bidang, dan telstur. Serta } \\
\text { prinsip desain kesatuan, } \\
\text { proporsi, dan keselarasan. }\end{array}$ \\
\hline
\end{tabular}

Gorga : Jurnal Seni Rupa

Volume 10 Nomor 02 Juli-Desember 2021 p-ISSN: 2301-5942 | e-ISSN: 2580-2380

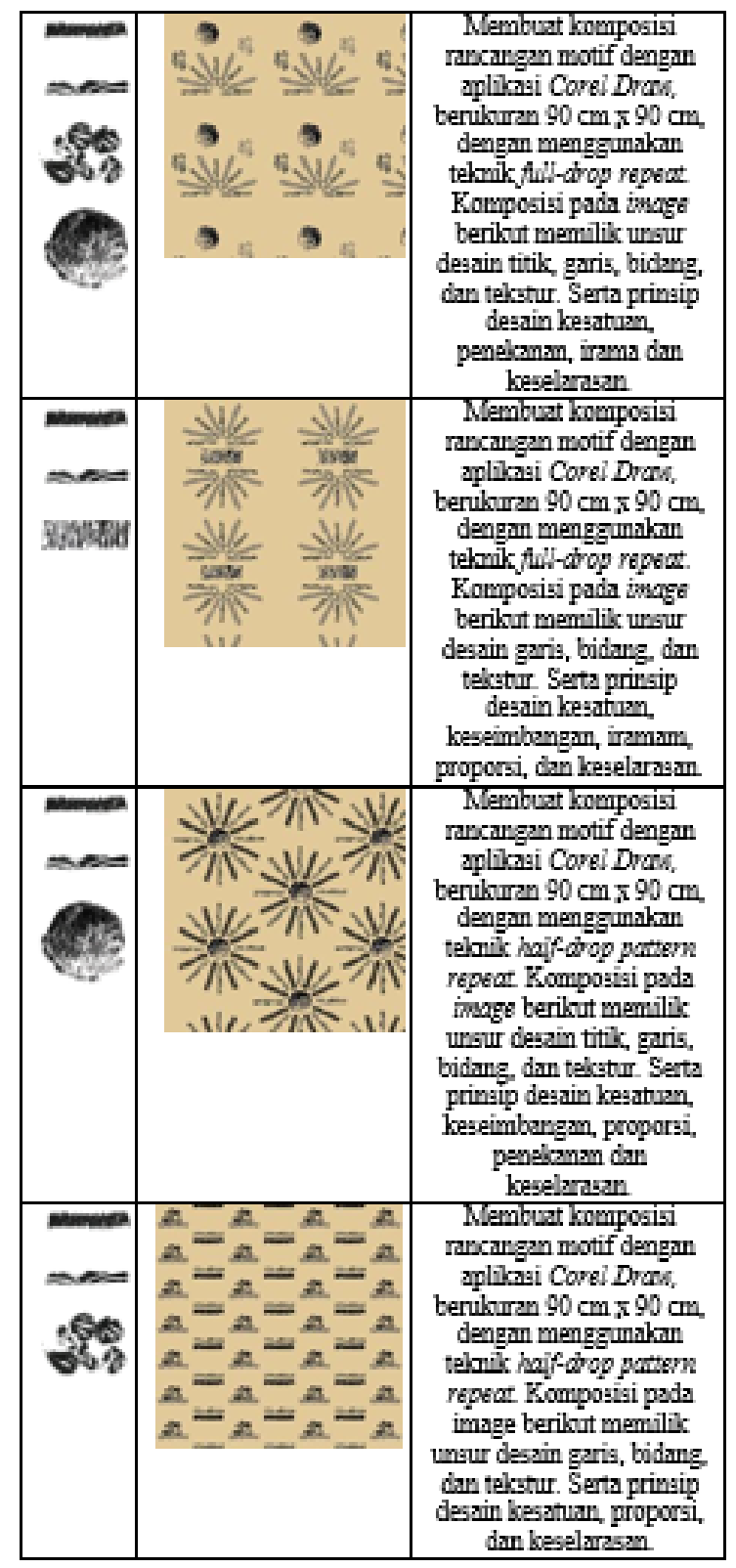

(Dumamika, 2021)

\section{3). Eksplorasi Terpilih}

Adapun hasil eksplorasi lanjutan yang sudah diaplikasikan pada kain berdasarkan hasil pertimbangan eksplorasi yang telah dilakukan sebelumnya, sebagai berikut: 


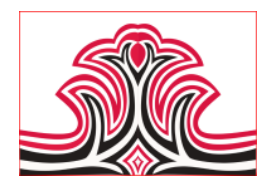

Tabel 3. Eksplorasi Terpilih

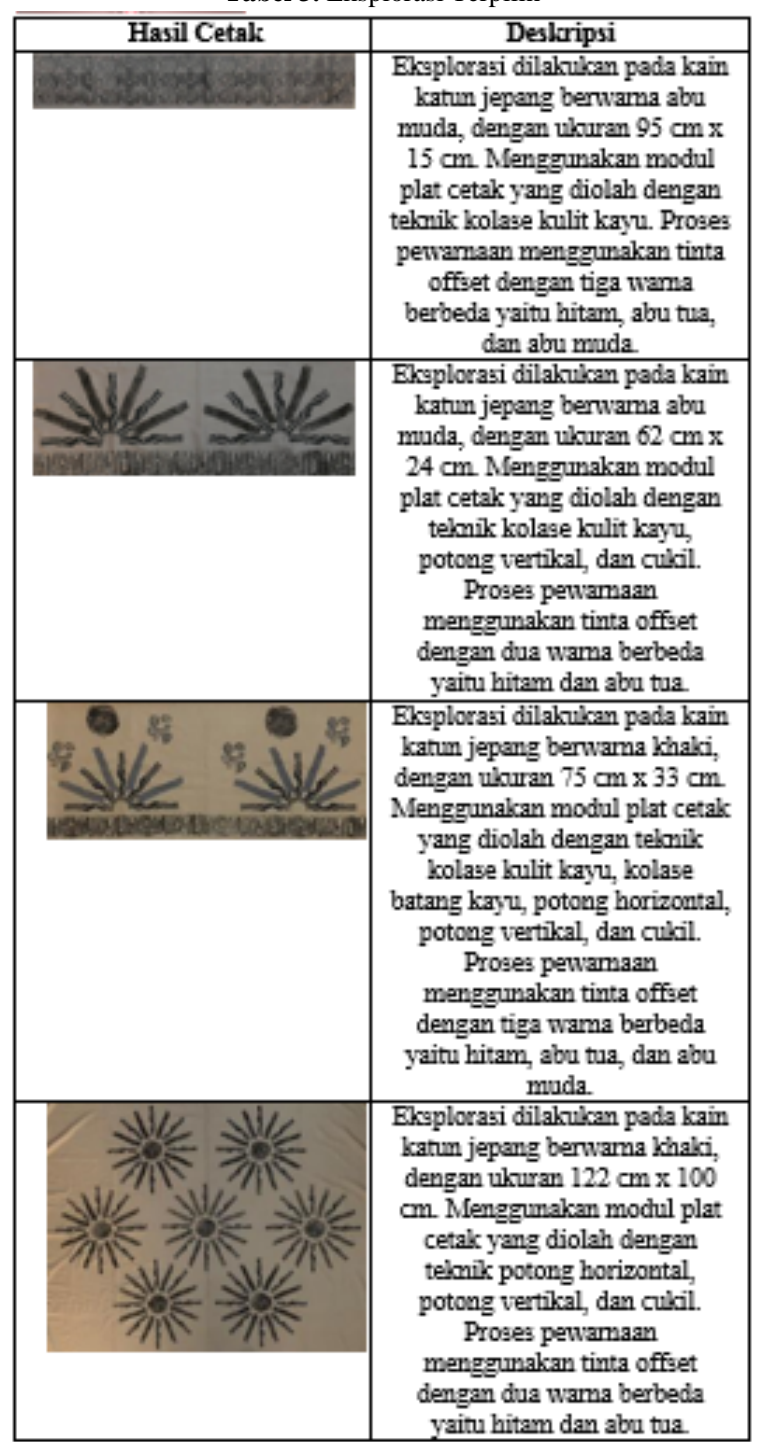

(Dumamika, 2021)

\section{4). Konsep Perancangan Produk}

Desain produk terinspirasi dari gabungan tema spirituality pada Indonesia Trend Forecasting 21/22 dan beberapa brand lokal yaitu BIASA, IMAJI Studio, dan renóa. Perubahan pola pikir manusia pada berbagai aspek kehidupan, seperti lebih menghargai lingkungan sekitar.

Dalam menghasilkan produk ini, peneliti menjadikan brand BIASA, Imaji Studio, dan renóa sebagai referensi dalam pembuatan desain seperti konsep, teknik, dan potongan. Berdasarkan hasil analisa, brand BIASA dan IMAJI Studio merupakan brand dengan konsep zero waste yang mengangkat budaya Indonesia. Brand ini memiliki ciri khas yang sama yaitu produk yang dihasilkan berupa poduk handmade, juga menggunakan teknik block printing untuk menghasilkan motif sederhana pada produk. Siluet dan potongan dari brand ini adalah pakaian loose dengan
Gorga : Jurnal Seni Rupa

Volume 10 Nomor 02 Juli-Desember 2021 p-ISSN: 2301-5942 | e-ISSN: 2580-2380

potongan lurus dan nyaman untuk dipakai sehari-hari. Sedangkan brand renóa memiliki ciri khas desain sederhana, namun dengan potongan dan detail yang elegan dan stand out. Brand ini menciptakan produk yang mendorong rasa percaya diri wanita yang bekerja.

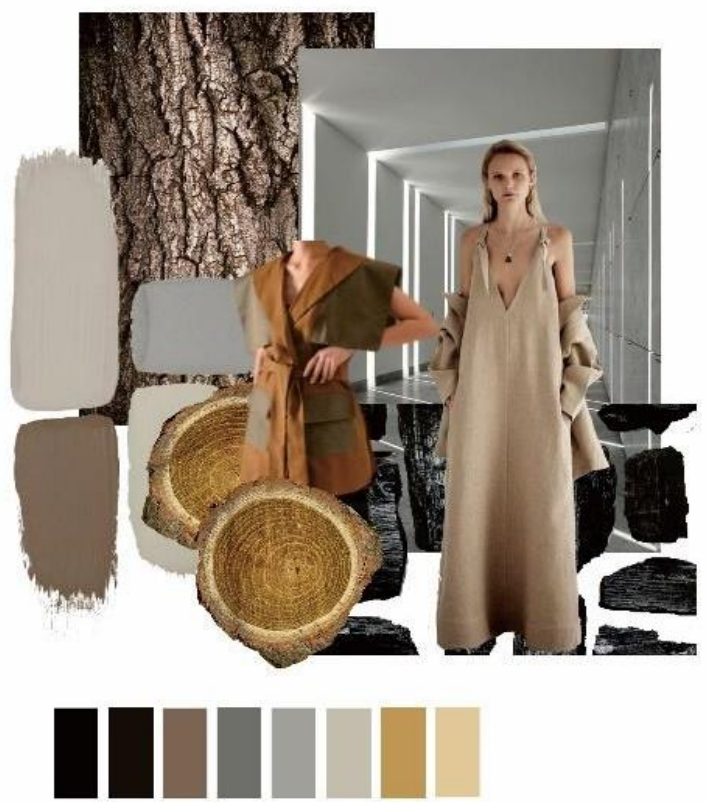

Gambar 4. Image Board Konsep Perancangan (Dumamika, 2021)

\section{(1). Deskripsi Konsep}

Konsep koleksi merupakan perancangan karya hasil motif dengan teknik block printing menggunakan plat cetak kayu bekas kebakaran hutan Kalimantan Barat yang diimplementasikan pada produk fashion berupa pakaian ready to wear. Memperlihatkan potongan dan desain bergaya klasik dari timur, elegan, dan sederhana. Dituangkan dalam bentuk pakaian praktis kekinian, berbahan dasar katun, dan menggunakan warna-warna earthy. Koleksi pakaian yang dibuat untuk berbagai kegiatan, dapat membuat wanita tampil beda saat bekerja dan bisa dipakai untuk after-office hangout, juga memberikan kebebasan saat memakainya.

\section{(2). Target Market}

Konsumen yang dituju adalah wanita dengan rentang usia 18-35 tahun, yang berprofesi sebagai model, aktris, dan dokter. Status sosial konsumen ada di bagian menengah ke atas dengan pendapatan minimal $\mathrm{Rp}$. 15.000.000/bulan. Dari segi geografis, konsumen yang dituju adalah mereka yang berdomilisi di kota metropolitan seperti Jakarta, Bandung, dan Bali. Karakteristik dari konsumen yang dituju merupakan konsumen yang anggun, sederhana, berpendidikan, memiliki rasa peduli yang tinggi, ambisius, dan memiliki hobi seperti travelling, berkarya, dan bergaya di depan layar. Konsumen juga mampu 


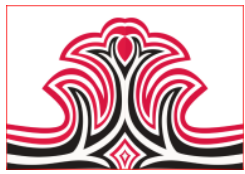

mengekspresikan kepeduliannya melalui fashion dan tertarik dengan produk lokal.

Acuan dalam perancangan penelitian ini adalah konsumen yang memiliki gaya pakaian yang simple dan nyaman. Konsumen memiliki sifat yang anggun, sederhana, agak tertutup, dan menyukai ketenangan. Konsumen juga suka menghabiskan waktu dengan membaca, jalan-jalan ke alam, dan membuat karya. Konsumen memiliki gaya hidup sehat, suka mengapresiasi budaya, dan memiliki kepedulian pada kekayaan alam Indonesia.

\section{(3). Desain Produk}
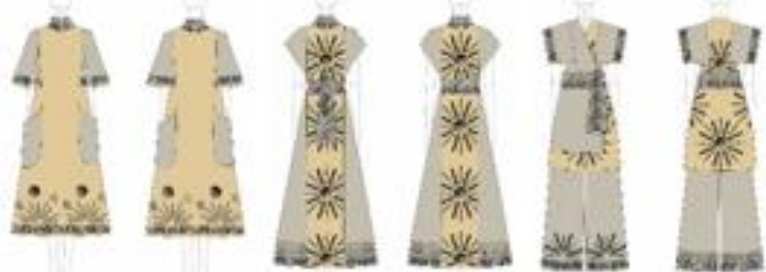

Gambar 5. Desain Produk (Dumamika, 2021)

\section{Pembahasan}

Hasil dari eksplorasi yang telah dilakukan yaitu modul plat cetak block printing yang dihasilkan dari teknik potong, kolase, dan cukil pada kayu bekas kebakaran hutan, dengan jenis pewarna oil-based (tinta offset), berpotensi untuk dijadikan komposisi rancangan motif. Komposisi rancangan motif dibuat dengan berbagai jenis pengulangan motif yang mencakup unsur dan prinsip desain, sehingga menghasilkan rancangan motif yang lebih menarik. Kemudian rancangan motif ini diimplementasikan pada lembaran kain dan pakaian ready to wear kekinian.

Berdasarkan hasil analisa dan konsep perancangan yang akan direalisasikan, desain produk berupa pakaian ready to wear untuk wanita yang tinggal di kota metropolitan dan sibuk bekerja. Produk menggunakan kain katun jepang dengan potongan busana loose dan desain bergaya timur, rapi, elegan, dan sederhana. Motif pada pakaian dibuat dengan teknik block printing menggunakan plat cetak alternatif yaitu kayu bekas kebakaran hutan, dengan pengkomposisian motif yang tidak terlalu penuh. Nuansa warna earthy yaitu turunan warna abu, khaki, dan hitam digunakan untuk mengingatkan pemakai akan lingkungan.

Produk dibuat dengan agar pemakai dapat tampil modern dan tetap merasa nyaman saat bekerja maupun saat hangout. Selain itu juga berdasarkan beberapa pertimbangan yaitu warna pada hasil eksplorasi dengan kain katun jepang dan tinta offset terlihat jelas, kain
Gorga : Jurnal Seni Rupa

Volume 10 Nomor 02 Juli-Desember 2021 p-ISSN: 2301-5942 | e-ISSN: 2580-2380

dapat memperlihatkan visual tekstur dan karakteristik kayu bekas kebakaran hutan, selain itu kain katun jepang juga memiliki tekstur bahan yang halus dan nyaman saat dipakai.

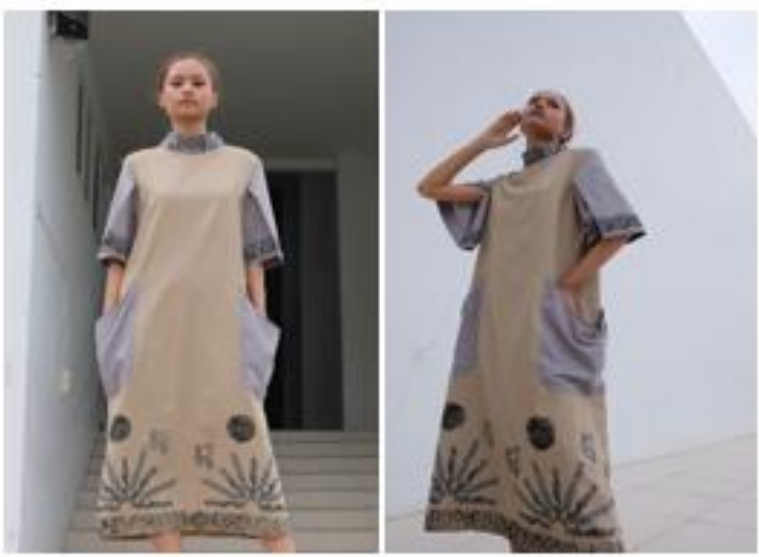

Gambar 6. Visualisasi Produk Desain 1 (Dumamika, 2021)

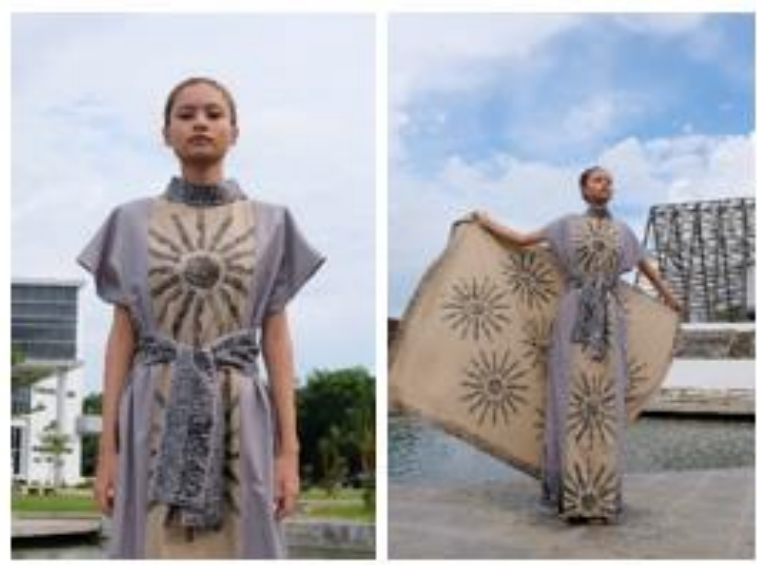

Gambar 7. Visualisasi Produk Desain 2 (Dumamika, 2021)
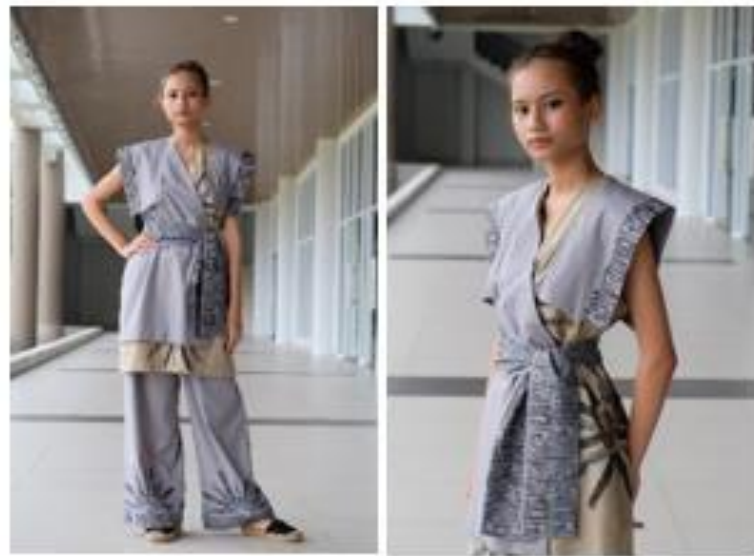

Gambar 8. Visualisasi Produk Desain 3 (Dumamika, 2021) 


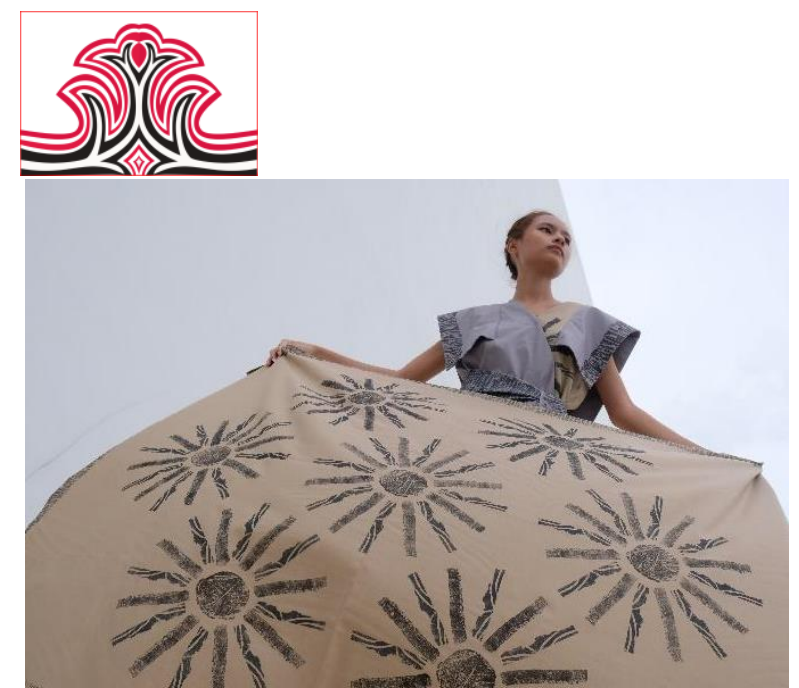

Gambar 9. Visualisasi Lembaran Tekstil 1 (Dumamika, 2021)

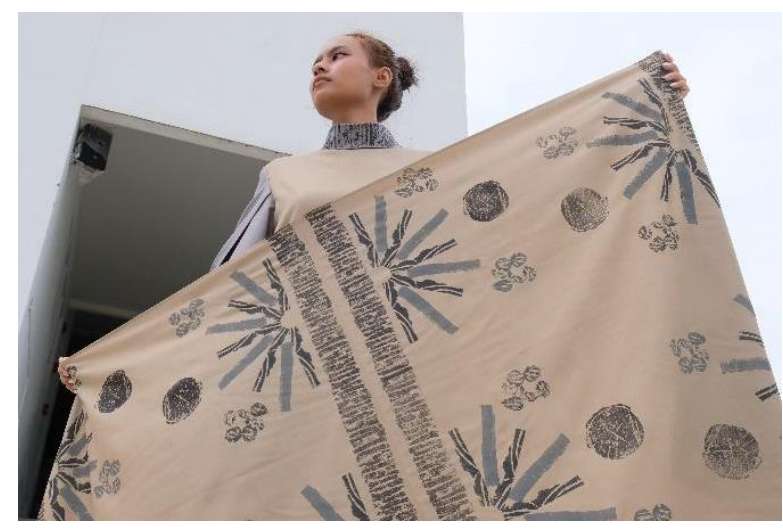

Gambar 10. Visualisasi Lembaran Tekstil 2 (Dumamika, 2021)

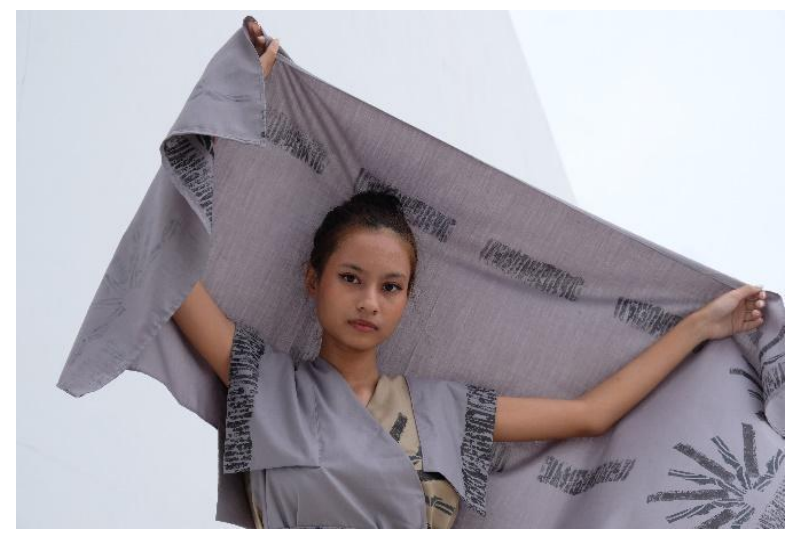

Gambar 11. Visualisasi Lembaran Tekstil 3 (Dumamika, 2021)

\section{KESIMPULAN DAN SARAN}

\section{Kesimpulan}

Berdasarkan penelitian yang telah dilakukan, peneliti menemukan beberapa kesimpulan diantaranya yaitu: 1). Kayu bekas kebakaran hutan Kalimantan Barat dengan jenis kayu akasia berukuran diamtere $2-8 \mathrm{~cm}$ berpotensi untuk dimanfaatkan sebagai material plat cetak alternatif yang diolah dengan teknik potong secara vertikal maupun horizontal, cukil dengan arah serat vertikal maupun horizontal, dan kolase dalam rangka mengembangkan teknik block printing, karena kayu ini memiliki permukaan yang dapat menghasilkan tekstur dan bentuk baru. 2).
Gorga : Jurnal Seni Rupa

Volume 10 Nomor 02 Juli-Desember 2021 p-ISSN: 2301-5942 | e-ISSN: 2580-2380

Perancangan komposisi motif harus dibuat dengan susunan warna, bentuk, dan ukuran modul berbeda agar dapat memberi kesan motif yang dinamis dan tidak monoton. Komposisi motif yang dicetak dengan teknik block printing pada kain katun jepang menggunakan tinta offset dapat memperlihatkan karakter visual dari kayu bekas kebakaran hutan Kalimantan Barat yang baru dan unik, karena struktur kainnya yang rapat. Selain itu, kain katun jepang juga memiliki tekstur serat yang halus saat bersentuhan dengan kulit dan nyaman untuk dipakai sehari-hari. 3). Motif yang dihasilkan dengan teknik block printing dapat diimplementasikan pada pakaian ready to wear. Pemilihan siluet dan potongan busana yang sederhana dilakukan agar fokus pakaian tertuju pada bagian motif dengan teknik block printing. Penempatan motif pada pakaian bagian pinggir maupun tengah harus seimbang dilakukan dengan berbagai pertimbangan, agar hasil cetak terlihat lebih menonjol dan menjadi pusat perhatian produk. Pengaplikasian teknik block printing harus dilakukan dengan hati-hati dan teliti karena dilakukan secara manual yang cukup beresiko untuk terjadi kesalahan saat mencetak.

\section{Saran}

Berdasarkan penelitian yang telah dilakukan, peneliti memiliki beberapa keterbatasan. Saran peneliti untuk penelitian selanjutnya yaitu gunakan material alternatif yang lebih kuat dan diolah dengan teknik lain yang dapat memperlihatkan karakteristik lain yang lebih unik, melakukan eksplorasi lebih mendalam pada pewarna dan kain yang digunakan seperti menggunakan material-material alami agar tidak menghasilkan limbah yang berbahaya untuk lingkungan.

\section{DAFTAR RUJUKAN}

Adi, S. P., Susanti, N., \& Panggabean, M. N. R. (2020). Cetak Tinggi dan Pengaplikasiannya (I. G. N. T. Marutama \& M. K. M. Saat (eds.); 1 st ed.). Surakarta: UNS Press.

Dumamika, Tione Afifaya. (2021). "Pengaplikasian Teknik Block Printing dengan Material Kayu Bekas Kebakaran Hutan". Hasil Dokumentasi Pribadi: 1 Januari s.d 30 Oktober 2021, Kalimantan Barat.

Eskak, E., \& Sumarno. (2016). Peningkatan Nilai Tambah pada Cacat Batang Kayu dengan Kreasi Seni. Dinamika Kerajinan Dan Batik, 33(2), 133-144.

Ganguly, D., \& Amrita. (2013). A Brief Studies On Block Printing Process In India. Man-Made Textiles in India, 41(6), 197-203.

Kafka, F. J. (1973). Batik, Tie Dyeing, Stenciling, Silk Screen, Block Printing: The Hand Decoration of Fabrics. USA: Dover Publications. 
Kementerian Lingkungan Hidup dan Kehutanan Republik Indonesia. (2018). Mengubah Limbah Kayu Hutan Rawa Gambut Bekas Kebakaran Menjadi Arang Kompos dan Cuka Kayu. www.menlhk.go.id (diakses tanggal 24 April 2021).

Lestari, S. B. (2014). Fashion sebagai Komunikasi Identitas Sosial di Kalangan Mahasiswa. Ragam Jurnal Pengembangan Humaniora, 14(3), 225238.

Media Indonesia. (2019). Olah Limbah Kayu, Solusi Atasi Pembakaran Lahan. www.mediaindonesia.com. (diakses tanggal 24 April 2021).

Needleman, D. (2018). The Ancient Art of Jaipur Block Printing, and What It Means to India. https://www.nytimes.com/2018/05/18/tmagazine/block-print-jaipur-india.html (diakses tanggal 1 Mei 2021).

Puspitawati, S., \& Ramadhan, M. S. (2019). Pengaplikasian Teknik Block Printing Dengan Inspirasi Motif Dari Kebudayaan Suku Baduy. ATRAT: Jurnal Seni Rupa, 7(3), 205-214. https://jurnal.isbi.ac.id/index.php/atrat/article/do wnload/925/695

Qodriyatun, S. N. (2014). Kebijakan Penanganan Kebakaran Hutan dan Lahan. Info Singkat Kesejahteraan Sosial, VI(06), 9-12.

Rahman, D. (2017). Seni Grafis Indonesia Kembali ke “Jalan Masif". Brikolase, 9(2), 90-97.

Rohani. (2017). Meningkatkan Kreativitas Anak Usia Dini Melalui Media Bahan Bekas. Jurnal Penelitian Dan Pengembangan Pendidikan Anak Usia Dini, $\quad 5(2), \quad$ 137-145. https://doi.org/10.30870/jpppaud.v4i2.4653.

Safitri, R., \& Rachmat, G. (2016). Studi Kelayakan Kayu Bekas Landasan Peti Kemas sebagai Elemen Interior Lepas. ATRAT: Jurnal Seni Rupa, 4(3). 243-252.

SiPongi Karhutla Monitoring Sistem. (2020). Rekapitulasi Luas Kebakaran Hutan dan Lahan (Ha) Per Provinsi Di Indonesia Tahun 20162021. www.sipongi.menlhk.go.id (diakses tanggal 20 Oktober 2020).

The Kindcraft. (2020). Introduction to Indian Block Printing: Anokhi Museum in Jaipur India. www.thekindcraft.com (diakses tanggal 22 Desember 2020).

Trisnawati, T. Y. (2016). Fashion sebagai Bentuk Ekspresi Diri dalam Komunikasi. Jurnal The Messenger, 3(2), 36-43. https://doi.org/10.26623/themessenger.v3i2.268.

Waddell, G. (2004). How Fashion Works: Couture, Ready-to-Wear and Mass Production. Journal of Chemical Information and Modeling, 53(09), 0000 . 